\title{
Childhood Obesity and Academic Achievement among Male Students in Public Primary Schools in Kuwait
}

\author{
Ahmed Abdelalim ${ }^{\mathrm{a}}$ Nawras Ajaj ${ }^{\mathrm{a}}$ Abdulrahman Al-Tmimy ${ }^{\mathrm{a}}$ \\ Maytham Alyousefi $^{\mathrm{a}}$ Sulaiman Al-Rashaidan ${ }^{\mathrm{a}}$ Majeda S. Hammoud ${ }^{\mathrm{b}}$ \\ Abdullah Al-Taiar ${ }^{a}$ \\ Departments of a Community Medicine and Behavioural Sciences and ${ }^{b}$ Paediatrics, Faculty of Medicine, \\ Health Sciences Centre, Kuwait University, Jabriya, Kuwait
}

\section{Key Words}

Childhood $\cdot$ Obesity $\cdot$ Students $\cdot$ Academic performance $\cdot$ Kuwait

\begin{abstract}
Objective: The aim of this study was to investigate the association between childhood obesity and student academic performance in the classroom setting. Subjects and Methods: A multi-stage cluster random sampling was used to select a representative sample of 1,213 fifth-grade students in male public schools. Height and weight were measured using a standard protocol. Overweight was defined as BMI $\geq 85$ th but $<95$ th percentile, while obesity as $\geq 95$ th BMI percentile, using growth charts provided by the Centre for Disease Control and Prevention (2000). Data on each student's academic performance and sociodemographic factors were extracted from school records. Of the 1,213 students, 147 were absent on the day the survey was conducted. Therefore, the analysis was based on 1,066 students. Of the 1,066 students, 67 did not have previous school records because they were new in the school; hence the association between school performance and obesity was based on 999 students. Results: The prevalence of obesity was 186 (17.4\%, 95\% Cl: 15.2-19.9\%) while the prevalence of overweight was
\end{abstract}

232 (21.8\%, 95\% Cl: 19.3-24.4\%). There was no significant association between obesity and academic performance after adjusting for sociodemographic factors. Parental education was the most important predictor for high academic performance in the classroom setting. Conclusion: There is no association between obesity and academic performance in the classroom setting among boys in Kuwait. With the lack of evidence of a relationship between childhood obesity and academic performance, using high performance as a measure of success in prevention initiatives cannot be justified.

Copyright $\odot 2011$ S. Karger AG, Basel

\section{Introduction}

The prevalence of childhood obesity is increasing at a dramatic rate [1-4], although recent reports suggest that it seems to have flattened recently in Western countries [5-7]. Currently, it is estimated that $31.8 \%$ of school children are overweight and $7.9 \%$ are obese in Europe [3]. Childhood obesity is associated with serious long-term medical consequences such as type 2 diabetes [8], hypertension, cardiovascular diseases, and osteoarthritis in adulthood [9]. Several important short-term adverse effects on growth, blood pressure, blood lipids, glucose me-

\section{KARGER}

Fax +4161306 1234

E-Mail karger@karger.ch

www.karger.com
(C) 2011 S. Karger AG, Basel

1011-7571/12/0211-0014\$38.00/0

Accessible online at:

www.karger.com/mpp
Dr. Abdullah Al-Taiar

Department of Community Medicine and Behavioural Sciences

Faculty of Medicine, Kuwait University, Box 24923

Safat 13110 (Kuwait)

Tel. +965 2498 6553, E-Mail altaiar@ hsc.edu.kw 
tabolism [10, 11], and respiratory problems such as asthma and obstructive sleep apnea, have also been reported $[12,13]$. Moreover, childhood obesity has been suggested to be the sole risk factor for myocardial infarction at a young age [14] and has been linked to negative self-image, decreased self-esteem [15], and lower health-related quality of life $[16,17]$.

In addition to the medical and psychological consequences of obesity among children, several studies have investigated the association of childhood obesity and the intelligence of children [18] or performance at schools [19-23]. A recent literature review described the findings of studies that examined the association between IQ and childhood obesity, and reported that the association was inconsistent or controversial [18]. Another literature review on the association between childhood obesity and academic achievement concluded that the number of studies is limited and the relationship is unclear [22]. The controversy remains, with a more recent study reporting that overweight children had significantly lower mathematics and reading test scores compared to normal weight children in the third grade, although the differences became insignificant after adjusting for socioeconomic status and maternal education [20]. Another study of Canadian children reported no difference in mathematics performance between children who were always obese and those who were never obese [24]. In fact, being obese during pre-school and then normal weight during primary school was associated with better performance in mathematics. Thus, the association between childhood obesity and students' academic performance remains controversial, despite the increasing prevalence of obesity among school children. This study aimed to explore the association between obesity and students' academic performance among males in public primary schools in Kuwait.

\section{Subjects and Methods}

Kuwait has a sex-segregated public educational system, and of the 214 public primary schools, 107 are male schools distributed in six governorates. The study population consisted of male students at fifth grade because this is the grade at which reliable and valid grades reflecting academic achievement in the classroom setting are first available. For logistic reasons the study was conducted in male public schools only.

A multi-stage cluster random sampling was used to select a representative sample of children at the fifth-grade level in male public schools in all governorates. Power calculation showed that selecting 1,100 students would provide more than $90 \%$ power to detect a difference of 5 grades (on $0-100 \%$ scale) in each study subject between obese and non-obese, assuming that $20 \%$ of the students are obese and the mean (SD) of students' grade in each study subject is $75 \%$ (15\%). The number of students selected from each governorate was based on the relative size of each governorate judged by the number of male children in the age group 5-9 years. Using the list of male public schools, a random sample of schools was selected using randomly generated numbers. The number of schools in each governorate was selected based on the number of students required in each governorate assuming that the average number of students at fifth grade in each school is approximately 120 students. It was decided to recruit one third of the students in each school, and as a result the total number of schools that were selected was 28 schools. Some selected schools had more students than the average number (120 students), and recruiting one third of students in each school resulted in the selection of 1,213 students of whom 147 were absent on the day the survey was conducted ( $87.9 \%$ response). In each school, the list of students in the fifth grade was used to select a systematic random sample of students. On arrival, a list of all students at fifth grade was sought in each school, and a random number was generated using a calculator as a random start and then every third student was selected.

Weight was measured using a portable digital weight floor scale (Beurer ${ }^{\mathrm{TM}}$ ) with weighing capacity from 1 to $150 \mathrm{~kg}$, accuracy $\pm 100 \mathrm{~g}$. Children were weighed barefoot and wearing light clothes. Height was measured to the nearest $0.5 \mathrm{~cm}$ using a portable wall-mounted stadiometer (SECATM) with the child's heels, back, and occiput touching the vertical bar as the horizontal bar was brought down closely touching the vertex. Weight and height measurements were taken in the school clinics that were activated in anticipation of a concurrent swine flu epidemic.

Data on each student's performance were extracted from school records, specifically, student's grades (on a scale from 0 to $100 \%$ ) in mathematics, science, and Arabic literature, in addition to the total grades. Similarly, data on the date of birth, nationality (Kuwaiti and non-Kuwaiti), parental educational level (illiterate, can write and read, primary, intermediate, high school, and higher education), type of housing (annex, apartment, villa and traditional Arabic house), child's living arrangements (both parents, mother only, stepfather, stepmother, and others), and whether the child has a chronic disease (yes, no) were all extracted from records kept in the schools. These records are completed and submitted by the parents every year.

Data were entered and analyzed using Statistical Package for Social Sciences (SPSS) version 16. Out of 1,066 who were present on the day of the survey, 67 had no grades because they were new to their current schools. Thus, the investigation of the association between obesity and academic performance was based on 999 students, but the prevalence of obesity and overweight was based on 1,066 students. Data on continuous variables were checked for normality, and means (SD) were reported if data were normally distributed or medians and IQR otherwise. Kruskal-Wallis was used to test the difference in students' grades by BMI categories with differences showing values of $p<0.05$ deemed to be statistically significant with no correction for multiple testing of the hypothesis. BMI was calculated by dividing weight in kilograms by height in meters squared, i.e. BMI = weight $(\mathrm{kg}) \div$ height $(\mathrm{m})^{2}$. BMI-for-age was calculated by means of weight, height, age, and gender as determined by the growth charts provided by the Centre for Disease Control and Preven- 
Table 1. Sociodemographic characteristics of the 1,066 students at fifth grade in male public schools in Kuwait

\begin{tabular}{|c|c|}
\hline Sociodemographic characteristics & $\mathrm{n}(\%)$ \\
\hline Age (mean $\pm S D)$, years & $10.3 \pm 0.4$ \\
\hline \multicolumn{2}{|l|}{ Nationality } \\
\hline Kuwaiti & $781(85.0)$ \\
\hline Non-Kuwaiti & $138(15.0)$ \\
\hline Subtotal & $919(100.0)$ \\
\hline Data not found & 147 \\
\hline \multicolumn{2}{|l|}{ Father's educational level } \\
\hline Illiterate & $2(0.3)$ \\
\hline Can write and read & $7(0.9)$ \\
\hline Primary & $17(2.1)$ \\
\hline Intermediate & $153(19.1)$ \\
\hline Secondary & $204(25.5)$ \\
\hline Higher education & $416(52.1)$ \\
\hline Subtotal & $799(100.0)$ \\
\hline Data not found & 267 \\
\hline \multicolumn{2}{|l|}{ Mother's educational level } \\
\hline Illiterate & $10(1.2)$ \\
\hline Can write and read & $30(3.7)$ \\
\hline Primary & $22(2.7)$ \\
\hline Intermediate & $111(13.9)$ \\
\hline Secondary & $166(20.7)$ \\
\hline Higher education & $462(57.8)$ \\
\hline Subtotal & $801(100.0)$ \\
\hline Data not found & 265 \\
\hline \multicolumn{2}{|l|}{ Type of housing } \\
\hline Annex & $6(0.7)$ \\
\hline Apartment & $228(28.3)$ \\
\hline Arab House & $101(12.5)$ \\
\hline Villa & $472(58.5)$ \\
\hline Subtotal & $807(100.0)$ \\
\hline Data not found & 259 \\
\hline \multicolumn{2}{|l|}{ With whom does the student live? } \\
\hline Both parents & $727(90.2)$ \\
\hline Mother only & $62(7.7)$ \\
\hline Stepmother only & $9(1.1)$ \\
\hline Stepfather only & $1(0.1)$ \\
\hline Others & $7(0.9)$ \\
\hline Subtotal & $806(100.0)$ \\
\hline Data not found & 260 \\
\hline \multicolumn{2}{|c|}{ Does the student have chronic condition or disease? } \\
\hline Yes & $93(10.7)$ \\
\hline No & $773(89.3)$ \\
\hline Subtotal & $866(100.0)$ \\
\hline Data not found & 200 \\
\hline
\end{tabular}

Data not found: these were not in the information sheets in the schools.
Table 2. Prevalence of overweight and obesity among 1,066 students at fifth grade in male public schools in Kuwait

\begin{tabular}{lrll}
\hline Governorate & $\mathrm{n}$ & $\begin{array}{l}\text { Overweight }^{1} \\
\mathrm{n}(\%)\end{array}$ & $\begin{array}{l}\text { Obesity }^{2} \\
\mathrm{n}(\%)\end{array}$ \\
\hline Capital & 134 & $40(29.8)$ & $29(21.6)$ \\
Hawali & 227 & $52(22.9)$ & $35(15.4)$ \\
Al-Farwaniya & 264 & $53(20.1)$ & $56(21.2)$ \\
Mubarak Al-Kbeer & 78 & $14(17.9)$ & $11(14.1)$ \\
Al-Ahmadi & 239 & $44(18.4)$ & $40(16.7)$ \\
Al-Jahra & 124 & $29(23.4)$ & $15(12.1)$ \\
\hline Total & 1,066 & $232(21.8)$ & $186(17.4)$ \\
\hline \multicolumn{2}{c}{${ }^{1}$ Overweight was defined as $\geq 85$ th but <95th BMI percentile. } \\
\multicolumn{2}{c}{ Obesity was defined as $\geq 95$ th BMI percentile. } \\
\hline
\end{tabular}

tion (2000) using the inbuilt function in STATA (StataCorp). According to this approach, the prevalence of overweight is defined as $\mathrm{BMI} \geq 85$ th and $<95$ th percentiles, while obesity is defined as $\geq 95$ th BMI percentile. The term 'overweight' in this study does not include obese children. Age of children was calculated by subtracting the date of birth from the date on which the survey was conducted. For those with no records in the school, which meant that their date of birth was missing, the date of birth was assumed to be the average date of birth of the study group. In order to assess the impact of this assumption on the estimated prevalence of obesity, data were reanalysed assuming that the date of birth for this group was missing. Students' performances in mathematics, science, Arabic literature, and total performance were dichotomized using the medians, which were approximately $86 \%$. With this binary variable, unconditional logistic regression was used to investigate the association between students' academic performance as an outcome and obesity or overweight as the main exposure after adjusting for parental educational level and other confounders.

Confidentiality of the study subjects was ensured by anonymous data collections with no personal data such as names or addresses collected. Children at this age cannot provide consent but consent from the Ministry of Education and the School Principals was obtained.

\section{Results}

The sociodemographic characteristics of the study group are shown in table 1 . The mean and SD of age was $10.3 \pm 0.4$ years, with the majority of participants being Kuwaitis (781, 85\%). Of the 1,066 students, most (727, 90.2\%) live with both parents; 93 (10.7\%) students had a chronic disease condition as reported in the records completed by their parents.

The median weight was $35.5 \mathrm{~kg}$ (IQR 29.5-44.5), while the mean height was $138.6 \mathrm{~cm}$ (SD 6.8). The median BMI 
Table 3. Distribution of students' grades by BMI categories, Kuwait 2009

\begin{tabular}{lllll}
\hline & $\begin{array}{l}\text { Mathematics } \\
\text { median (IQR) }\end{array}$ & $\begin{array}{l}\text { Science } \\
\text { median (IQR) }\end{array}$ & $\begin{array}{l}\text { Arabic literature } \\
\text { median (IQR) }\end{array}$ & $\begin{array}{l}\text { Total mark } \\
\text { median (IQR) }\end{array}$ \\
\hline $\begin{array}{llll}\text { Normal } \\
\text { Overweight }\end{array}$ & $85.5(75.5-94.0)$ & $86.0(77.0-93.5)$ & $83.5(72.0-93.0)$ & $90.3(83.8-95.4)$ \\
Obese & $89.0(76.5-95.0)$ & $89.0(79.0-94.9)$ & $87.0(77.0-95.0)$ & $92.3(85.4-96.4)$ \\
\hline p value $^{*}$ & $83.0(71.5-92.0)$ & $85.0(73.0-92.5)$ & $84.0(71.0-92.5)$ & $89.5(82.1-94.8)$ \\
\hline
\end{tabular}

* Kruskal-Wallis test. IQR = Interquartile range.

Table 4. Association between students' performance ( $\leq$ median vs. $>$ median) at fifth grade in male public schools and obesity or overweight using unconditional logistic regression $(n=999)$

\begin{tabular}{lllll}
\hline & Mathematics & Science & Arabic literature & Total mark \\
\hline BMI & & & & \\
$\quad$ Normal & reference & reference & reference & reference \\
$\quad$ Overweight & $1.32(0.96-1.80)$ & $1.39(1.01-1.89)$ & $1.58(1.16-2.17)$ & $1.36(0.99-1.86)$ \\
$\quad$ Obese & $0.82(0.58-1.16)$ & $0.84(0.60-1.18)$ & $0.89(0.63-1.25)$ & $0.86(0.61-1.20)$ \\
Adjusted BMI & & & & \\
$\quad$ Normal & reference & reference & reference & reference \\
$\quad$ Overweight & $1.17(0.80-1.71)$ & $1.37(0.94-2.00)$ & $1.45(0.98-2.14)$ & $1.33(0.90-1.96)$ \\
$\quad$ Obese & $0.91(0.61-1.38)$ & $0.92(0.62-1.37)$ & $0.96(0.64-1.45)$ & $1.00(0.66-1.49)$ \\
\hline
\end{tabular}

Data presented as OR for high score with 95\% CI in parentheses.

${ }^{1}$ Adjusted for mother's and father's educational levels and nationality.

was 18.4 (IQR 16.0-22.8) while the median $\mathrm{z}$-score BMI was 0.7 (IQR -0.4 to 1.7 ).

The overall prevalence of childhood obesity was 186 (17.4\%; 95\% CI: 15.2-19.9\%) while the prevalence of overweight was 232 (21.8\%; 95\% CI: 19.3-24.4\%). The prevalence of obesity and overweight was 138 (17.7\%) and 170 (21.7\%), respectively, among Kuwaitis, while 22 (15.9\%) and 33 (23.9\%), respectively, among non-Kuwaitis ( $\mathrm{p}=$ 0.8 ). The prevalence of obesity and overweight remained unchanged after exclusion of those who had chronic disease conditions. There was no significant variation in the prevalence of obesity or overweight by parental education, although parents with level of education equal to secondary school or higher were more likely to have overweight but not obese children. The prevalence of obesity and overweight was significantly higher among students in the schools of the Capital in comparison to other governorates, with approximately more than half of the participating students being obese or overweight in the Capital (table 2). This remained evident after strat- ification by nationality, parental education, or type of housing.

The distribution of students' grades in mathematics, science, Arabic literature, and total grades by BMI categories is given in table 3 . There were significant differences in the medians of students' grades between different BMI categories, with overweight students being more likely to have higher grades compared to obese and normal weight students. Some of these differences remained significant after stratification by nationality.

The association between obesity and students' academic performance in mathematics, sciences, Arabic literature, and total performance before and after adjusting for potential confounders (mother's educational level, father's educational level and nationality) is shown in table 4. Other factors including type of housing, presence of chronic disease condition, and whether the child was living with both parents were not significant confounders. There was no association between BMI categories and students' performance after adjusting for parental 
education and other explanatory variables. In fact, adjusting for father's or mother's educational level alone was sufficient to explain the association between overweight and students' performance found in univariate analysis. Parents with a higher educational level were more likely to have children who are overweight but not obese in comparison to parents with lower educational level (23.6\% overweight and $17.9 \%$ obese vs. $16.8 \%$ overweight and $21.2 \%$ obese).

\section{Discussion}

The $17 \%$ prevalence of childhood obesity and $22 \%$ overweight of this study are consistent with the latest two studies on childhood obesity of $15 \%$ in the age group 10 14 years [4], and 20\% in the age group of 5-13 years [2]. Recent reports from developed countries suggest that the prevalence of childhood obesity is no longer increasing [5-7], which implies that preventive interventions were fruitful, thereby pointing out that these initiatives should be tested and used to reduce childhood obesity in Kuwait.

In our study, the finding that there was no association between childhood obesity and academic performance in mathematics, science, Arabic literature, or total performance, confirmed the previous study [24], which did not find an association between childhood obesity and academic performance. However, it is possible that the lack of association in our study was due to the fact that the examinations were not discriminating, since more than half of the students received grades above $86 \%$ in all subjects in the schools' curricula.

Although some studies found that childhood obesity is inversely related to students' academic performance [20], other studies found that obese children perform better in school, claiming that these children may try to counterbalance their negative self-image [23]. In a recent study, being obese in the pre-school years and then normal in primary school years was associated with improved mathematics performance [24]. In our study, overweight children performed marginally better than obese and non-obese children, but this could be explained by the confounding effect of parental educational level. The effect of parental education seems to have had a far stronger impact on academic performance than obesity or overweight. Most of the studies that reported an association between childhood obesity and performance found that adjusting for socioeconomic status made the link between obesity and academic performance insignificant $[20,25]$.
The way in which childhood obesity may affect students' academic performance has been open to speculation for a long time. Recently, psychosocial variables, such as weight-based teasing [26] and victimization and harassment from peers [27] have been suggested to mediate the effect of childhood obesity on academic performance. Overweight children may be prone to the low sense of worth that comes from being teased, bullied, or rejected by peers, and this may ultimately affect their academic performance. If this is the case, we anticipate the impact of childhood obesity on students' academic performance to be less obvious in areas where weight-based teasing and victimization is not a widespread problem, as here in Kuwait. It is also possible that obese children may develop sleep disorders which result in poor concentration and lead to poor performance at school [28]. Other studies have suggested that obese children are prejudged as low performers by their teachers [29] and others have suggested that obese children are more likely to miss school days [21] and hence receive lower grades than their non-obese peers.

One of the limitations of this study is that $12 \%$ of the students were absent. As obese children are more likely to be absent [21], this may result in underestimation of childhood obesity and also may conceal the association between childhood obesity and students' academic performance. Our findings also cannot be generalized to children in all age groups, female gender, or students in private schools.

\section{Conclusion}

Our findings did not show an association between childhood obesity and students' academic performance among male students in primary schools in Kuwait. The overall benefit from good physical fitness would justify the recommendation for schools to exert efforts to improve physical fitness and achieve ideal body weight, even if the association between childhood obesity and students' academic performance is not present. Nevertheless, further studies are needed to investigate the association between obesity and academic achievement in classroom settings because initiatives to combat childhood obesity have started using students' academic performance as a measure of success. 


\section{References}

$>1$ Ogden CL, Flegal KM, Carroll MD, Johnson CL: Prevalence and trends in overweight among US children and adolescents, 19992000. JAMA 2002;288:1728-1732.

$>2$ Sorkhou I, Al-Qallaf K, Al-Shamali N, Hajia A, Al-Qallaf B: Childhood obesity in $\mathrm{Ku}$ wait - prevalence and trends. Fam Med 2003; 35:463-464.

-3 Jackson-Leach R, Lobstein T: Estimated burden of paediatric obesity and co-morbidities in Europe. Part 1. The increase in the prevalence of child obesity in Europe is itself increasing. Int J Pediatr Obes 2006;1:26-32.

$>4$ El-Bayoumy I, Shady I, Lotfy H: Prevalence of obesity among adolescents (10 to 14 years) in Kuwait. Asia Pac J Public Health 2009;21: 153-159.

$\checkmark 5$ Ogden CL, Carroll MD, Flegal KM: High body mass index for age among US children and adolescents, 2003-2006. JAMA 2008; 299:2401-2405.

6 Olds TS, Tomkinson GR, Ferrar KE, Maher CA: Trends in the prevalence of childhood overweight and obesity in Australia between 1985 and 2008. Int J Obes (Lond) 2010;34: 57-66.

7 Salanave B, Peneau S, Rolland-Cachera MF, Hercberg S, Castetbon K: Stabilization of overweight prevalence in French children between 2000 and 2007. Int J Pediatr Obes 2009;4:66-72.

-8 Goran MI, Ball GD, Cruz ML: Obesity and risk of type 2 diabetes and cardiovascular disease in children and adolescents. J Clin Endocrinol Metab 2003;88:1417-1427.

$\checkmark 9$ Haslam DW, James WP: Obesity. Lancet 2005;366:1197-1209.

10 Wabitsch M, Hauner H, Hertrampf M, Muche R, Hay B, Mayer H, Kratzer W, Debatin KM, Heinze E: Type II diabetes mellitus and impaired glucose regulation in Caucasian children and adolescents with obesity living in Germany. Int J Obes Relat Metab Disord 2004;28:307-313.
11 Wiegand S, Maikowski U, Blankenstein O, Biebermann H, Tarnow P, Gruters A: Type 2 diabetes and impaired glucose tolerance in European children and adolescents with obesity - a problem that is no longer restricted to minority groups. Eur J Endocrinol 2004;151:199-206.

12 He QQ, Wong TW, Du L, Jiang ZQ, Qiu H, Gao Y, Liu JW, Wu JG, Yu IT: Respiratory health in overweight and obese Chinese children. Pediatr Pulmonol 2009;44:997-1002.

13 Tai A, Volkmer R, Burton A: Association between asthma symptoms and obesity in preschool (4-5 year old) children. J Asthma 2009;46:362-365.

14 El-Menyar AA, Gomaa MM, Arafa SE: Obesity: a risk factor for acute myocardial infarction with angiographically patent epicardial coronary vessels in an adolescent. Med Princ Pract 2006; 15:449-452.

15 Wang F, Wild TC, Kipp W, Kuhle S, Veugelers PJ: The influence of childhood obesity on the development of self-esteem. Health Rep 2009;20:21-27.

16 Hughes AR, Farewell K, Harris D, Reilly JJ: Quality of life in a clinical sample of obese children. Int J Obes 2007;31:39-44.

17 Tsiros MD, Olds T, Buckley JD, Grimshaw P, Brennan L, Walkley J, Hills AP, Howe PR, Coates AM: Health-related quality of life in obese children and adolescents. Int J Obes 2009;33:387-400.

$18 \mathrm{Yu}$ ZB, Han SP, Cao XG, Guo XR: Intelligence in relation to obesity: a systematic review and meta-analysis. Obes Rev 2010;11: 656-670.

19 D'Hondt E, Deforche B, De Bourdeaudhuij I, Lenoir M: Childhood obesity affects fine motor skill performance under different postural constraints. Neurosci Lett 2008; 440:72-75.
20 Judge S, Jahns L: Association of overweight with academic performance and social and behavioral problems: an update from the early childhood longitudinal study. J Sch Health 2007;77:672-678.

-21 Schwimmer JB, Burwinkle TM, Varni JW: Health-related quality of life of severely obese children and adolescents. JAMA 2003; 289:1813-1819.

22 Taras H, Potts-Datema W: Obesity and student performance at school. J Sch Health 2005;75:291-295.

23 Zoppi G, Luciano A, Vinco A, Residori P: Obesity in pediatrics: statistical analysis of school performance of obese children (in Italian). Pediatr Med Chir 1995; 17:559-561.

24 Carter MA, Dubois L, Ramsay T: Examining the relationship between obesity and math performance among Canadian school children: A prospective analysis. Int J Pediatr Obes 2010;5:412-419.

25 Chervin RD, Clarke DF, Huffman JL, Szymanski E, Ruzicka DL, Miller V, Nettles AL, Sowers MR, Giordani BJ: School performance, race, and other correlates of sleepdisordered breathing in children. Sleep Med 2003;4:21-27.

26 Krukowski RA, Smith West D, Philyaw Perez A, Bursac Z, Phillips MM, Raczynski JM: Overweight children, weight-based teasing and academic performance. Int J Pediatr Obes 2009;4:274-280.

27 Puhl RM, Latner JD: Stigma, obesity, and the health of the nation's children. Psychol Bull 2007; 133:557-580.

28 Gozal D: Sleep-disordered breathing and school performance in children. Pediatrics 1998;102:616-620.

29 Puhl R, Brownell KD: Bias, discrimination, and obesity. Obes Res 2001;9:788-805. 